\title{
A natureza da fotografia na fotografia da nafureza: o selvagem, a desmesura e a beleza do mundo
}

\section{RESUMO}

O artigo discute a relação híbrida da fotografia com a natureza, a partir da ideia de que essa relação articula memória e matéria, pela construção imaginária de paisagens e lembranças. A fotografia privilegia a representação do artificial em detrimento do natural. Mas é a representação da grandeza da paisagem e da precariedade do humano diante dela que revela a própria natureza da fotografia, ao pensar em si e sobre todas as coisas.

\section{PALAVRAS-CHAVE}

Fotografia

Representação

Natureza

The nature of photography in nature photography: wildness, incivility and the beauty of the world

\section{ABSTRACT}

The article discusses the hybrid relationship between nature and photography, from the idea that this relationship hinges memory and matter by the construction of imaginary landscapes and memories. The photography focus on representation of the artificial over the natural. But is the representation of the grandeur of the landscape and the precariousness of the human before it that reveals the very nature of photography, thinking about itself and about reality.

\section{KEYWORDS}

Photography

Representation

Nature

\author{
Paulo C. Cunha Filho \\ Professor do Programa de Pós-graduação em Comunicação da \\ UFPE/PE/BR \\ paulo@npd.ufpe.br
}

\section{Ana Farache \\ Doutoranda em Comunicação pela UFPE/PE/BR \\ anafarache@gmail.com}

Atento à progressiva degradação do pensamento arcaico, quase desesperado com os perigos associados ao esgotamento do sagrado no mundo contemporâneo, Píer Paolo Pasolini filmou Medéia, em 1969. Logo no início da narrativa o minotauro fala ao filho de 13 anos:

\footnotetext{
Não há nada de natural na natureza, meu pequeno. Guarde isso na sua mente. Quando a natureza te parecer natural, tudo terá acabado. E começará alguma outra coisa. Adeus céu, adeus mar [...] Que belo céu! Tão perto! Feliz! Diga, não te parece mesmo pouco natural qualquer pedacinho dele? Não te parece que pertence a um Deus? Assim como o mar, neste dia em que fazes 13 anos e estás pescando com os pés nas águas mornas? Olha atrás de teu ombro. O que vês? Talvez alguma coisa natural? Não, é uma miragem que percebes atrás de ti, com as nuvens que se espelham na água parada, pesada, das três da tarde. Olha lá longe, aquela linha escura sobre o mar, brilhante como o azeite, aquelas sombras de árvores e aqueles canaviais. Em cada ponto onde que teus olhos pousarem, estará escondido um Deus. E se por acaso ele não estiver, é porque deixou lá os sinais de sua presença sagrada. ${ }^{1}$
} 
Também é possível encontrar no território da fotografia aquilo que realça o minotauro de Pasolini. Matéria e imaginação, selvageria e ordem paradisíaca, a natureza é muito mais do que um mero tema, é muito mais uma categoria do pensamento fotográfico. E como categoria, evocar a natureza tanto é capaz de nos fazer entender o mundo quanto entender a própria fotografia. Pois longe de ser natural, a natureza é o espaço privilegiado de construção do imaginário fotográfico, como intuía perfeitamente Man Ray, ao dizer que não fotografa a natureza, mas sua fantasia: "É maravilhoso explorar os aspectos que sua retina não pode registrar" "

\section{Tudo é sagrado}

Há, na visão de Man Ray, a ideia de que a natureza que a fotografia tenta mostrar, retratar, dar sentido, não é um conjunto neutro, formado por plantas, pedras, rios e animais, posto diante dos olhos e das lentes dos fotógrafos - mas uma dimensão categórica desde sempre contaminada pelo imaginário. Mesmo quando expressamos que só desejamos - nada além disso registrar o que vemos com a fotografia, não conseguimos cegar o nosso olhar, que vê além do que pensamos e suplanta o que pensamos ver. Essa ideia aflora a cada vez que consideramos a diversidade de olhares que pairam sobre a imagem fotográfica.

Por outro lado, o que a fotografia é capaz de captar está intrinsecamente ligado a sua própria natureza, seus princípios, sua essência - ou seja, ao conjunto de elementos que a fazem ser o que ela é em seu aspecto material, em sua materialidade corpórea, mas também na sua dimensão metafísica - no que ela revela, às vezes não por mostrar, mas por escamotear. A fotografia materializa sua natureza ao se colocar em operação. É o pensamento se revelando enquanto pensante, na perspectiva de Plotino, que ensina que "pensar a si mesmo é pensar todas as coisas" ${ }^{3}$, como se a própria natureza falasse:

Eu contemplo - diz a Natureza - e o que produzo é obra de minha contemplação silenciosa; não é descrevendo figuras, mas sim contemplando que deixo cair de meu âmago as linhas das formas que desenham os corpos. Todas as coisas nasceram de uma contemplação. ${ }^{4}$
É incontestável que a fotografia herda da pintura a postura contemplativa. A busca de momentos e paisagens presentes na natureza, constituindo-se um dos fatores que mais motivaram os primeiros fotógrafos a perseguirem a fixação mecânica da imagem. Como sabemos, foi no verão de 1833 , durante sua lua-demel, que Talbot, desapontado com o resultado de seus desenhos da paisagem das montanhas em Bellagio, passou a procurar soluções de registro na química. "Como seria maravilhoso - sonhava ele - se essas imagens da natureza pudessem permanecer para sempre impressas em papel" ${ }^{5}$ - incrementando a investigação dos efeitos da luz do sol sobre o nitrato de prata e outros compostos. Ora, quatro anos após patentear sua principal descoberta (o calotype, em 1840), publica o primeiro livro ilustrado com fotografias e que recebe o título nada fortuito de The Pencil of Nature.

A expansão do uso do calotype permitiu a muitos artistas apreender aspectos da paisagem - e assim desenvolver um pensamento fotográfico específico sobre a natureza, na medida em que extrapolavam as condições da pintura e do desenho. Nesse contexto, uma das mais impressionantes coleções de imagens do século XIX é a produzida por David Octavius Hill e Robert Adamson entre 1843 e 1847, atualmente preservadas na Glasgow University Library. Leafless nature oak trees (Figura 1), de David Octavius Hill, faz parte da coleção.

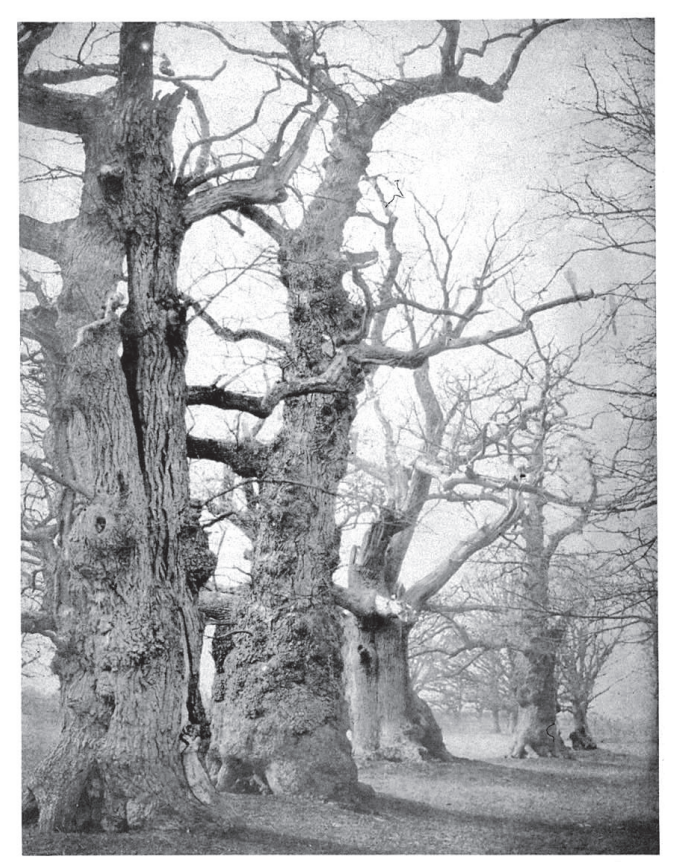

Figura 1 - Leafless nature oak trees. 
Essa é uma das muitas imagens produzidas a partir da abrangência (ou limitação) da própria natureza fotográfica da época. Essa imagem pensa duplamente: pelo que expõe do mundo e pela contingência material a que está circunscrita, na medida em que já incorpora a dimensão imaterial que estabelece uma ideia ambígua da natureza, oscilando entre o arcaico e o moderno. A natureza aprisionada no retângulo da fotografia, rebelde e controlada, presente e ausente a um só tempo.

\section{A fotografia é como a imagem da confenção, impondo a estética do enquadramento e, ao mesmo tempo, a insinuação de um resto que escapa, que vai além, abrindo as portas do imaginário.}

\section{Ansel Adams vai ao Yosemife...}

Em 1935, Ansel Adams, aos 33 anos, escreve uma carta apaixonada e exigente para Dorothea Lange ${ }^{6}$ :

Querida Dorothea,

A fotografia, quando diz a verdade, é magnífica. Mas ela pode ser deturpada, deformada, reduzida e comprometida mais do que qualquer outra arte. Porque o que fica diante das lentes sempre passa a ilusão da realidade; mas o que é selecionado e capturado pelas lentes pode ser tão falso quanto qualquer mentira totalitária [...] As conotações de boa parte da fotografia documental é - para mim - excessivamente rígida. [...] Eu me sinto como se quisessem me ensinar que certas coisas têm um sentido. [...] Eu me sinto manipulado e conduzido a uma fórmula de pensamento e comportamento político-social. Eu sinto as implicações da ideia de que uma fotografia sem função político-social não teria valor para a população. Eu sinto o muito óbvio desprezo dos ele- mentos de beleza [...] E eu acho importante trazer para as pessoas as provas da beleza do mundo, da natureza e do homem, tanto como oferecer-lhes um documento de feiúra, miséria e desespero. [...] Você foi uma das poucas que colocou emoção humana suficiente em seu trabalho para tornar esse tipo de imagem suportável para mim. Eu quero e tento pensar sobre você como uma artista - o que você é; isso é uma forma de ver o mundo muito mais importante do que qualquer mera extensão de um movimento sociológico.

Amor, Ansel.

A carta de Adams está contaminada pelos múltiplos interesses que marcaram a sua vida como artista, educador, músico, escritor e ecologista avant la lettre ${ }^{7}$. Há nela, ao mesmo tempo, desconfiança com a fotografia de documentação social - cujas características lhe pareceriam passíveis demais de serem manipuladas - e essa profissão de fé num outro tipo de fotografia: " $\mathrm{Eu}$ penso ser tão importante levar ao povo a prova da beleza do mundo da natureza e do homem quanto oferecerlhe o documento da feiúra e do desespero" ${ }^{8}$. A carta estabelece um curioso elo entre uma das mais famosas fotógrafas documentaristas do mundo, Dorothea Lange, e aquele que veio a ser considerado um dos mais instigantes fotógrafos da paisagem americana. A carta premonitória, apontando para a possibilidade de desvios ideológicos da fotografia documental, foi escrita um ano antes de Lange produzir, para a Farm Security Administration, a antológica e polêmica sequência da qual isolaria a fotografia denominada posteriormente Migrant Mother. O que fez Lange para produzir essa imagem genial? Como ela contou muitos anos depois, aproximase da mulher que acalenta e protege os filhos, a ponto de retirar toda a natureza do quadro:

Eu vi e me aproximei da faminta e desesperada mãe, como se atraída por um imã. Eu não lembro como expliquei a minha presença ou minha câmera para ela, mas lembro que ela não perguntou nada. Eu fiz cinco fotografias, trabalhando cada vez mais perto, avançando na mesma direção. Eu não perguntei nem o nome dela nem a sua história. Ela me disse sua idade, que tinha 32. Ela me disse que estavam sobrevivendo comendo 
vegetais congelados dos campos próximos, e pássaros que as crianças caçavam. ${ }^{9}$

$\mathrm{Na}$ imagem selecionada por Lange, nada dos campos e das plantações congeladas, nada dos pássaros que as crianças famintas caçavam para comer, apenas o drama humano resumido nos corpos da mãe e das crianças marcadas pela depressão, contido na intensa troca de olhares entre a mulher e a fotógrafa. Um ano antes, Adams parecia contestar esse recorte para propor em outra dimensão, aquela que se definia pelo ponto de vista aparentemente oposto, da paisagem e da representação da beleza.

É conhecido o vínculo de Ansel Adams com os parques naturais americanos, notadamente o Yosemite ${ }^{10}$, que visitava com freqüência para criar e ou para isolarse nos momentos mais duros, desde 1916 - quando, aos catorze anos, o fotografou pela primeira vez com uma Kodak Number 1 Box Brownie. Muitas análises da obra de Adams, aliás, estabelecem uma relação genética entre a formação do olhar do fotógrafo e o êxtase visual provocado pelo Yosemite. O resultado desse destino cruzado são paisagens e naturezas mortas que continuam a despertar reconhecimento universal de uma obra singular, constituída por imagens em preto e branco que exploram o poder grandioso da natureza. Esse reconhecimento é marcado, inclusive, por um persistente sucesso comercial que faz com que as imagens de Adams continuem sendo vendidas em livros, cartões postais, selos, pôsteres e calendários. Curioso: Adams nunca aceitou considerar suas imagens comerciais como parte de sua obra artística: Entre 1930 e o final dos anos 1970, assim como seus contemporâneos Edward Weston e Paul Strand, Adams trabalhou produzindo imagens para catálogos de lojas femininas, publicidade e Coloramas gigantes para a Eastman Kodak Company.

Admirador do trabalho de pioneiros da fotografia de natureza do século XIX, como Timothy O'Sullivan e Carleton Watkins, Adams sempre louvou a capacidade que eles tiveram de levar e trabalhar com placas de vidro em circunstâncias totalmente adversas, no calor extremo e na poeira, transportando câmeras pesadas no lombo de mulas, para produzir fotografias que revelaram a desmesura da paisagem americana. Portanto, as fotografias da natureza de Adams não valem pela originalidade do tema já registrado por outros, mas, sobretudo, pelo adensamento de uma perspectiva que perdia o caráter geográfico, documental, para atingir dimensões semânticas próprias, a partir da importação e a subversão da tradição pictórica. Adams assumia que perseguia a beleza - num sentido muito particular, como diria em outra carta à amiga Dorothea Lange, em $1953^{11}$ :

Não tenho medo do termo "beleza". Com esse termo não me refiro ao bonito. Mas à intensidade e à claridade. Eu não consigo ver de que maneira a omissão da beleza poderia dar qualquer resultado.

O diálogo entre Adams e Lange sintetiza a articulação intensa que a fotografia promove entre a ideia de natureza e a de paisagem. O jogo que a pintura e posteriormente a fotografia estabeleceram é de construir as diversas representações da natureza através do artifício da paisagem, como explica Anne Cauquelin ${ }^{12}$ :

De um lado, a paisagem "interdita" a natureza; de outro, um comentário infinito força essa interdição a se apresentar como essência natural da paisagem [...] Desse modo, os criadores se esforçam para mostrar/ocultar à mesma medida que os simples amadores equilibram pelo instinto, desconhecendo o que não querem saber. [Os criadores] procedem a apagamentos e marcações, e, produzindo vastos conjuntos ou modestos pormenores, esforçam-se para fazer ver o que não se pode ver, fazer sentir o que não se pode tocar, para sugerir o invisível: a estrutura oculta que preside à existência da paisagem.

\section{0 assombro diante do inculto}

A própria ideia de paisagem é uma construção cultural. Foi estabelecida, sobretudo, a partir das práticas pictóricas holandesas do século XVII e desenvolvida posteriormente no contexto da pintura inglesa no século XVIII. Mesmo distantes no tempo e no espaço, esses momentos vincularam a ideia de paisagem às vistas onde a natureza se reporta às mudanças provocadas pelos humanos no ambiente natural. De forma ampla, inclui, de um lado, mares, campos, rios; de outro, conecta o ambiente intocado a jardins, prédios e canais.

Em grande medida, portanto, a natureza está vinculada à ideia de "mundo material", no senso comum de mundo-em-que-vive-o-ser-humano e que existe independentemente das atividades humanas. Quando se imagina que a natureza pode sintetizar um conjunto de 
elementos materiais (mares, montanhas, árvores, animais, etc.) impõem-se a grandeza do que se chama "cenário natural". Ocorre que a natureza também extrapola essa síntese geomorfológica, material, na medida em que se refere também ao universo inteiro e seus fenômenos, assim como aquilo que compõe a substância do ser, a essência.

Foi essa tensão que permitiu à pintura ocidental cunhar o termo natureza morta, quando certas composições representam coisas ou seres inanimados (animais mortos, frutos em cestas, flores num vaso). Eis, então, a morte, o desaparecimento integrado à representação da natureza, e não somente a natureza material, mas o que se convencionou chamar, muito depois, de natureza humana, na qual a finitude assume um lugar privilegiado para dar conta do mistério da existência. Ora, a filosofia da natureza, tão antiga quanto a filosofia em geral, nasce da "busca de um princípio fundamental capaz de explicar a existência de todas as coisas" ${ }^{13}$. A ideia de physis como totalidade e substância do mundo material tem um viés metafísico, na medida em que a totalidade transcende a possibilidade de experimentação ${ }^{14}$. Assim, a physis opera conceitualmente no domínio da uma ordem imanente, como se apreende em Sêneca, num contexto que privilegia "a tradição mítica grega de unidade entre espírito e natureza, e, ao mesmo tempo, [o início de certo] estranhamento entre o ser humano pensante e o ser natural ou a totalidade dos demais seres da natureza, ou seja, a natureza em sua totalidade" ${ }^{15}$. Se a concepção imanente se dilui na modernidade (como se inquietava Pasolini) é por dar lugar ao atomismo, ou seja, "a vontade de atomizar a natureza inteira" 16.

A posição imanentista também foi prejudicada pela ambiguidade medieval, que pressupunha esse lugar criado por Deus, mas apartado dele; as duas naturezas opostas de Agostinho: a natura naturans, que é Deus e a potência de criação, e a natura naturata, o território da obra criada. Trata-se da ideia do Livro da Natureza, escrito pelo dedo de Deus (scriptus digitus Dei). Nesse patamar, estamos a um passo da matematização do mundo e da concepção mecanicista da natureza do século XVII (a Grande Máquina, o Grande Relógio) na qual está em jogo a concepção da natureza como movimento contínuo, ou determinação. Como técnica e como ideologia, a fotografia nascente se encaixa perfeitamente nessa tradição, mantida até hoje, de máquina de visão, de lenteolho, de imagem-verdade. A posição da fotografia será ainda reforçada com o retorno ao modelo imanentista de Schelling, que abandona a ideia de natureza enquanto objeto e a separação cartesiana entre res extensa (natureza) e res cogitan (sujeito).

\section{A fotografia já surge como expressão de que a nafureza é o sujeito, produzindo sua própria represenfação.}

Por isso, a fotografia participa, desde o século XIX, das diversas representações da natureza e, de alguma forma, reitera a tradição instituída pela pintura, na medida em que preserva muito dos seus padrões de operação.

\begin{abstract}
A fotografia de paisagem herdou em grande medida as convenções de composição da pintura de paisagem. Em geral, fotografias de paisagem são retângulos laterais - e não é apenas acidente que o "formato paisagem" é usado para descrever fotografias onde a largura é maior do que a altura. Do ponto de vista da composição, a "regra de ouro" das proporções um terço/dois terços frequentemente é obedecido, assim como as regras da perspectiva. ${ }^{17}$
\end{abstract}

Herdeira dessa tradição, uma multidão de fotógrafos, a partir do instante em que teve nas mãos as ferramentas fotográficas, decidiu voltar-se para essas regiões que pareciam intocadas pela ação humana - ou, pelo menos, livres dessa dimensão que passamos a considerar como cultural. Nesse processo de aproximação do olhar e das regiões incultas, a fotografia vem constantemente colaborando com a instituição de dimensões arquetípicas, simbólicas e míticas da própria natureza, ou seja, as dimensões cultas do natural:

Os fotógrafos do século XIX eram artistas que foram liberados da tarefa de reproduzir as maravilhas da natureza - suas câmeras passaram a fazê-lo para eles. Eles puderam concentrar seus esforços criativos para explorar cenas apavorantes em composições surpreendentes que, quando capturadas na película, produziam obras de arte dramáticas. $^{18}$ 
Ansel Adams, na primeira metade do século XX, permitiu uma nova compreensão da natureza ao fotografar. Por exemplo, o Zabriskie Point, no Vale da Morte californiano, quando a natureza passou a estabelecer uma relação alegórica com a paisagem na dimensão grandiosa e patriótica que passaria posteriormente a ser adotada pelo filmes do gênero western. O natural seria a desmesura, a ausência (ou a pequenez) do homem, o lugar do indomável. Mas Adams estava longe de ser um pioneiro. É possível discutir a diferença do seu trabalho do ponto de vista da maestria com a qual registrou a paisagem americana, mas nunca enquanto o primogênito dessa longa tradição de representar a grandeza da paisagem e a precariedade do humano diante dela. Edward S. Curtis registrou, no final do século XIX, um índio pescador da tribo Hupa (Figura 2).

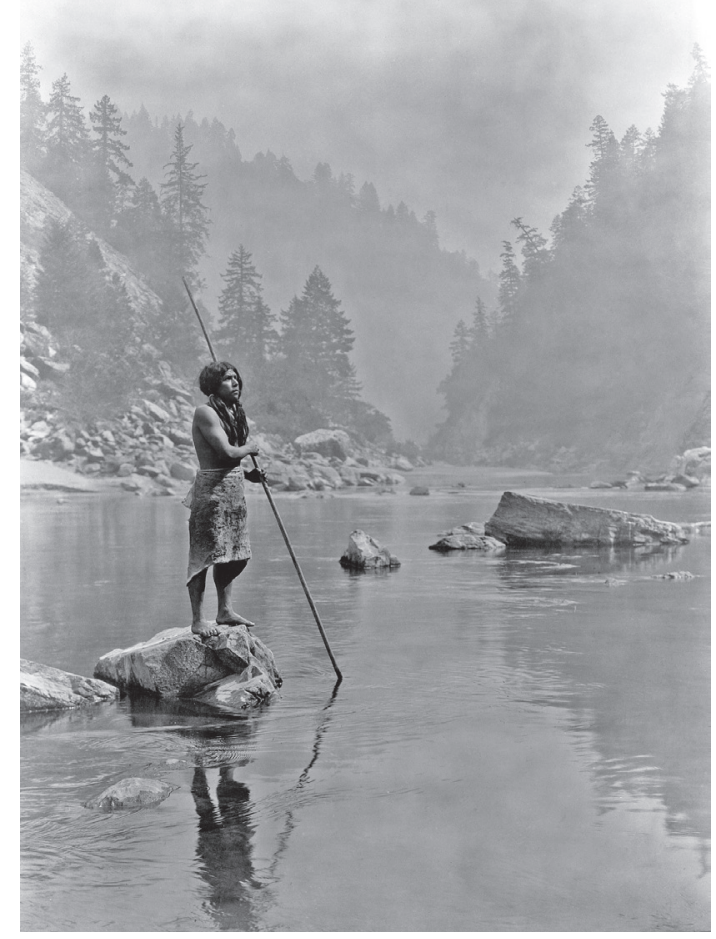

Figura 2 - Índio pescador de Edward S. Curtis.

A imagem desse índio do noroeste da Califórnia, registrado pelo etnógrafo amador Curtis, contemplando a terra justamente no momento em que seu povo começava a ser apartado dela, diz muita coisa da natureza e da fotografia. Da noção de pano de fundo, com o céu nublado, as montanhas e o rio servindo de cenário para a exibição da solidão do índio, à questão da pose - que não deixa de ser a forma artificial de ser natural -, passando pelo que não está registrado materialmente: o fim de uma era, de um espaço, de uma cultura e mesmo de uma ideia da natureza, violentamente substituída por outras ideias. E dentro dessas novas ideias da natureza, o índio se torna figuração.

\section{A natureza da fotografia}

Há muitos exemplos da presença da fotografia na constituição das várias dimensões da natureza (e, na mesma medida, a presença da natureza na definição do que é a fotografia). Em 1955, o fotógrafo de moda Richard Avedon, criou uma das imagens mais célebres já produzidas para o mundo fashion, ao fotografar, para a Maison Dior, a modelo Dovima, com um longo e belo vestido preto e branco à frente de um grupo de enormes elefantes - exacerbando o contraste entre a dimensão selvagem e a civilização.

Assim como na fotografia de Avedon,

\section{a relação da fotografia com a nafureza é híbrida ao articular memória e matéria na construc̣ão imaginária de paisagens e lembranças.}

É fácil constatar como a fotografia tentou privilegiar o artificial, em detrimento do natural. Estatisticamente, é muito mais expressiva a quantidade de imagens que representam as cidades, os equipamentos - o trabalho, as dores e os prazeres dos humanos - do que aquilo que possa ser circunscrito na dimensão "natural" da natureza. Não faltam tentativas de explicação para essa preferência: a fotografia nasce no quadro da revolução industrial, é um dispositivo de representação entre tantos outros dispositivos, e manteria sua coerência ao representar os seus próprios domínios - ou seja, o próprio mundo artificial de onde surgiu.

No entanto, o privilégio do artificial na representação fotográfica não passa de ilusão, uma miragem, como diz o minotauro de Pasolini. Mero efeito de uma leitura muito parcial da produção fotográfica, como demonstra a clássica fotografia de Ilse Bing, de 1931, chamada Autoretrato com espelhos e na qual vemos a própria fotógrafa e sua câmera, de frente e de perfil, representando-se através de um jogo de espelhos e de olhares cruzados. Fugindo de todo natural, a fotógrafa induz o olhar do espectador a 
seguir um determinado caminho no qual só têm sentido os elementos do próprio dispositivo fotográfico. Tudo parece artifício nessa imagem de Ilse Bing, tudo tende ao apagamento da natureza: espaço construído e fechado, máquina, espelhos, objetos sobre uma mesa. $\mathrm{E}$, no entanto, a natureza se impõe na representação do artificial, resistindo nos seus restos: partes de um corpo de mulher e vagos destinos de olhares, evocando o que corpo e olhar conseguiram manter de natural no mundo do artifício.

Nesta perspectiva, assumimos o vínculo constitutivo da fotografia com a natureza, na medida em que a reprodutibilidade técnica das imagens nasce pela necessidade de apreensão da natureza e de suas artimanhas: Como voam os pássaros? Como galopam os cavalos? Cientistas e amadores do século XIX fizeram avançar a fotografia apenas para responder a questões dessa ordem. Colaborando, inclusive, como Eadweard Muybridge, com o surgimento do cinema ao reproduzir imagens em sequência para estudar os movimentos dos animais. E parece curioso observar que quando pretendeu estudar o humano, Muybridge retratou homens e mulheres despidos, em atitudes desprovidas de todo pathos, andando ou saltando como bichos aprisionados nos limites da jaula do dispositivo fotográfico. As séries de Muybridge evocam essa impossibilidade cruel de manter a natureza viva na representação, de poder apenas evocá-la e de circunscrever o homem na condição do afastamento definitivo do natural. Resta a queda, o mergulho no artifício, a vitória da máquina. Resta ainda a própria ideia de captura.

Mesmo a fotografia erótica nascente não se furtava em estabelecer a relação ambígua entre o humano e o natural. Como no caso da figura 3, um anônimo de 1905, em que duas mulheres nuas posam ao lado de um falso caracol gigante no quadro de um igualmente falso cenário de lago.

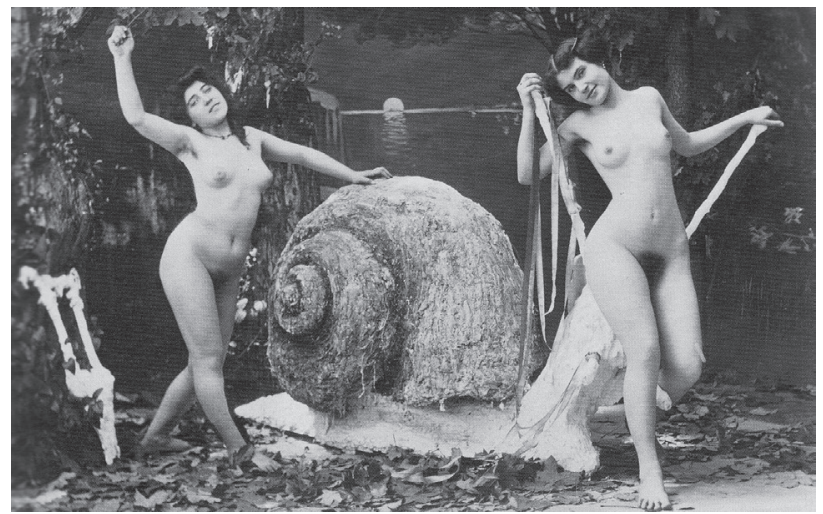

Figura 3 - Mulheres nuas posam ao lado de um falso caracol gigante.

Essa imagem de autor desconhecido mostra como estamos constituindo, nessa perspectiva, acervos gigantescos, e de várias ordens, capazes de servir à reinterpretação do conflito entre máquina enatureza, entre o domador e as feras. A primeira câmera cinematográfica construída pelos irmãos Lumière recebeu a curiosa denominação de Domitor (domador, aquele capaz de sujeitar, domesticar, amansar, subjugar). A fotografia e, depois dela, o cinema, acabaram participando do projeto moderno de organizar o natural, retirando do selvagem aquilo que poderia ser medido, calculado, hierarquizado, assim como os botânicos e os enciclopedistas já vinham fazendo com desenhos e aquarelas. A imagem técnica reinventou a natureza.

Todo esse jogo complexo remete a uma simbologia da liberdade, na qual a fotografia pensa o natural enquanto impossibilidade. Ou seja, a natureza é também um artifício do humano. A cada passo, a cada imagem, ao aliar concretude e transcendência, a fotografia reafirma o seu caráter técnico-expressivo e abre espaço para a participação dos artefatos como motores do imaginário. A fotografia, acessoriamente, induz a uma reflexão sobre o papel das diversas estruturas de mediação para o estabelecimento da dimensão simbólica. De acordo com Stephen Shore, em The nature of Photographs,

Fotógrafos baseiam suas fotografias em modelos mentais. Esses modelos podem ser muito rígidos, como quando, por exemplo, um fotógrafo só reconhece o pôr-do-sol como digno de ser fotografado. O outro extremo seria o modelo flexível. Em geral, o modelo é inconsciente, mas o fotógrafo pode controlá-lo, tornando-se consciente dele. ${ }^{19}$ 
Também, Roland Barthes estabeleceu os princípios de uma possível relação da fotografia com a natureza através da análise da produção do fotógrafo Daniel Boudinet, que retratou os campos que se espalham nos arredores das cidades francesas. Num artigo pouco conhecido, intitulado singelamente Sobre algumas fotografias de Daniel Boudinet, Barthes começa afirmando que "a foto é como a palavra: uma forma que quer imediatamente dizer alguma coisa. Nada a fazer: eu sou obrigado a ir ao sentido, pelo menos a um sentido" ${ }^{20}$.

O que defende Barthes nesse texto? Que a fotografia de Boudinet busca reproduzir um significante ao mesmo tempo afastado do "artístico" e do "natural", capaz de escapar do "estetismo" e do "naturalismo", que seriam dimensões melhor associadas à pintura e à literatura. Barthes conta como, quando ainda matinha as fotos de Boudinet numa pasta, preparando-se para escrever o texto de apresentação, várias pessoas que por acaso olhavam as imagens, diziam: "Como é belo!". O que o levou a imaginar um caminho de interpretação:

A história contada por essas doze imagens começa por uma fascinação [ravissement no original $^{21}$ ] (já que eu exclamo); mas o que me toma não é um espetáculo, uma cena, uma vista, é uma matéria de folhagem. Um tecido delicado: a substância ao mesmo tempo cerrada e leve, desordenada e centralizada: essas florações verticais sem ar, sem céu, inexplicavelmente me fazem respirar; elas me elevam a "alma" (como teríamos dito cem anos atrás, mas a alma é sempre o corpo) e portanto eu quero também me afundar no obscuro da terra: ou seja, uma moiré de intensidades.

Ao olhar para as fotos de Daniel Boudinet, Barthes observou o engajamento de diversas culturas: a cultura da terra, da geografia, da história, da ruralidade - um "lugar fechado, coerente, inteligível", a ideia de que a representação pode constituir "quadros pacíficos", repousantes e de maneira que muitas vezes esse tipo de imagem muito mais do que afirma, "produz" a paz.

Há uma evidência perseguida por Barthes (1995) nas imagens de Daniel Boudinet que se refere ao rural, classificado como "espaço onde o produto humano e o produto natural se indiferenciam, formam uma mesma substância", ou a natureza enquanto "massa vegetal" na qual o homem se insere como camponês ("o trabalho conquista seu valor mítico"). Barthes chega dessa forma ao essencial: "Uma fotografia só vale se desejamos (mesmo na recusa) o que ela representa". Esse desejo de uma substância unificada, imanente (a cultura harmonizada com a natureza, o repouso harmonizado com o trabalho) é o que se vê igualmente numa imagem anônima muito mais antiga, do século XIX (Figura 4).

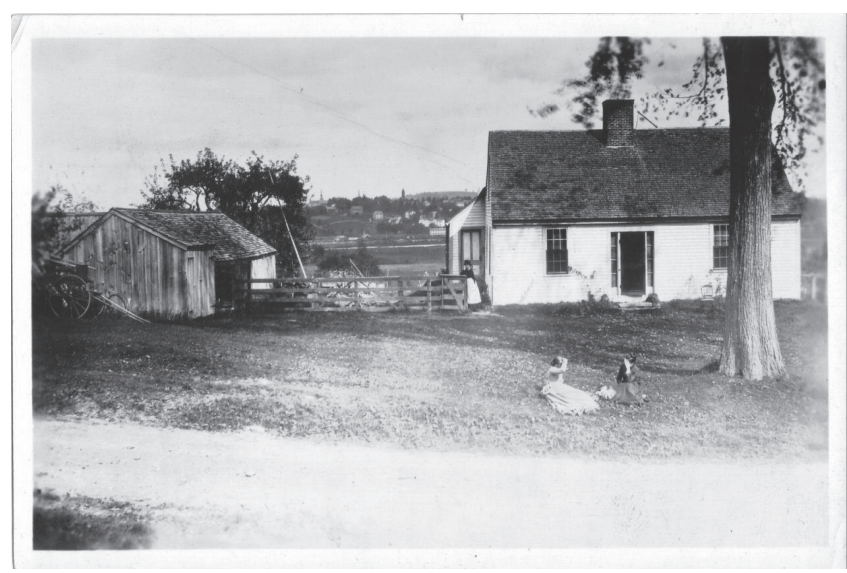

Figura 4-As filhas de Calvin Jenning desfrutando de uma tarde de verão.

A fotografia faz parte do Jennings Heritage Project Archives. Mostra duas filhas do diácono Calvin Jenning desfrutando de uma tarde de verão do ano de 1880 . Defensores da ideia de educação em casa, a família Jenning era também adepta da disciplina da vida do campo. Então, a fotografia que circula na cidade, nos meios burgueses, é um signo explícito desse paraíso distante, de uma ideia remota da natureza em harmonia com o nosso desejo de completude, certa noção de higiene.

\section{0 imaginário nafural}

Quais seriam então as questões fundamentais da constituição de um imaginário do "natural" e de sua dependência com as representações técnicas?

Como pano de fundo, o princípio da contradição (ou da complementaridade) que há na invenção tecnológica da natureza representada, há na dialética que impera na representação fotográfica da natureza: A do objeto técnico que cisma em estabelecer um vínculo com a pureza mítica do selvagem - ou, pelo menos, com o espaço intermediário do rural. Nessa busca pelo elo 
perdido, a representação fotográfica pensa tanto na perspectiva da religação quanto na da definição de seu próprio regime.

O olho artificial remete ao olho natural e só se justifica a partir dessa remissão. De modo que há uma deriva do imaginário que se sedimenta em níveis sucessivos de apreensão.

\section{A relação da fołografia com a nafureza evoca um essencialismo e solicita a compreensão de uma dinâmica na qual a construção do registro imagético dialoga e contribui para a própria instifuição do que se enfende nafureza.}

E essa compreensão, sempre provisória, se rebate sobre a natureza da fotografia, que deixa de ser registro para tornar-se usina de sentidos.

Não se trata de uma condição do passado da imagem técnica, mas uma dimensão que continua, como no trabalho do tcheco Josef Sudek, que fotografou naturezas mortas no seu estúdio e, através de sua janela, seu jardim e árvores. Suas fotos têm uma beleza suave, intimista, como se procurassem revelar uma beleza quase inacessível. Em Sudek, a luz é sempre "natural" - luz do sol, revelada pelo efeito da temperatura dessa luz sobre o vidro e sobre a paisagem (a neblina, o degelo). Foi dessa experiência que Sudek criou o conceito de "available light”, ou seja, a luz disponível, sem qualquer acréscimo de iluminação artificial, buscando um apagamento quase absoluto do artifício.

Tudo que está em torno de nós, vivo ou morto, aos olhos de um fotógrafo louco misteriosamente leva a diversas variações, de modo que um objeto aparentemente morto ressuscita através da luz ou pela força do seu entorno [...] Eu suponho que isso seja o lirismo. ${ }^{22}$
O que Sudek pensou, através da fotografia, foi até que ponto a natureza está efetivamente disponível para a imagem e o que essa disponibilidade quer, de fato, dizer. Ao fazer isso, Sudek participa da longa aventura fotográfica, que mostra que a natureza, ao se prestar à representação, obriga a fotografia a especular sobre aquilo que ela é capaz de capturar, de domar, e ao mesmo tempo, sobre a sua própria natureza. Se a natureza da fotografia são os seus princípios materiais e imateriais, se essa natureza é a própria essência da fotografia, então a fotografia se revela enquanto pensante, ao pensar em si e sobre todas as coisas.

\section{REFERÊNCIAS}

BARTHES, Roland. Sur des photographies de Daniel Boudinet. In: BARTHES, Roland. Oeuvres complètes 3. Paris: Seuil, 1995.

BEZERRA, Cícero Cunha. Compreender Plotino e Proclo. Petrópolis: Vozes, 2006.

CAUQUELIN, Anne. A invenção da paisagem. São Paulo: Martins Fontes, 2007.

FINN, David. How to look at photographs. New York: Harry N. Abrams, 1994.

GOBRY, Ivan. Vocabulário grego da filosofia. São Paulo: Martins Fontes, 2007.

GONÇALVES, Márcia. Filosofia da natureza. Rio de Janeiro: Jorge Zahar, 2006.

HUISMAN, Denis. Dicionário dos filósofos. São Paulo: Martins Fontes, 2001.

JOHNSON, Brooks. Photography speaks: 150 photographers on their art. Hampshire: Aperture Foundation, 2004.

JOHNSON, Drew Heath. Inspiration and Influence: The Visions of Ansel Adams. Disponível em: <http://www. tfaoi.com/aa/3aa/3aa325.htm>. Acesso em: 01 jan. 2008.

LA GRANGE, Ashley. Basic critical theory for photographers. Oxford: Focal Press, 2005.

LANGE, Dorothea. The assignment I'll never forget. In: NEWHAL, Beaumont (Ed.). Photography: essays and images. London: Secker and Warburg, 1980. 
SCHWARTZ, Auturo. Man Ray - the rigour of imagination. New York: Rizzoli, 1977.

WELLS, Liz. Photography: a critical introduction. London: Routledge, 1998.

\section{NOTAS}

1 Medeia, de Píer Paolo Pasolini, DVD Versátil, cód. 7895233146204, 1969.

${ }^{2}$ Man Ray, citado por Schwartz (1977, p. 323).

${ }^{3}$ Conferir em Bezerra (2006, p. 79).

${ }^{4}$ Citado por Huisman (2001, p. 789).

${ }^{5}$ Johnson (2004, p. 22).

${ }^{6}$ Johnson (2008).

7 O primeiro emprego fixo de Ansel Adams, em 1919, foi o de curador da Sierra Club Lodge, no Vale Yosemite. Essa associação o aproximou de vários grupos ecologistas da época. Adams foi inclusive diretor do Sierra Club durante 37 anos e um militante ativo da Wilderness Society, sempre permitiu que suas imagens fosse utilizadas em campanhas ambientais e chegou mesmo a atuar como lobista ambiental no Congresso do Estados Unidos.

${ }^{8}$ Johnson (2008).

${ }^{9}$ Lange (1980, p. 53).

${ }^{10} \mathrm{O}$ Parque Nacional Yosemite, na Califórnia, é uma das primeiras reservas selvagens dos Estados Unidos, com cerca de 1200 milhas quadradas de cachoeiras, sequóias e pradarias.

${ }^{11}$ Johnson (2008).
${ }^{12}$ Cauquelin, (2007, p. 166-167).

${ }^{13}$ Gonçalves (2006, p. 7).

${ }^{14} \mathrm{O}$ substantivo physis deriva do verbo phýo, que quer dizer, faço crescer, faço nascer e, na forma média, phýomai: eu broto, eu cresço, eu nasço. Dessa nascente, a natureza é compreendida como uma potência autônoma (por isso a primeira pessoa: eu nasço eu cresço [...]), capaz de organizar a vida inteira. É universal (a Ordem do Mundo, a lei geral de todos os fenômenos, a alma dos corpos) e é a "minha natureza", que embora individual está conectada ao Todo. Ver Ivan Gobry (2007, p. 115-118).

${ }^{15}$ Gonçalves (2006, p. 12).

${ }^{16}$ Gonçalves (2006, p. 21).

${ }^{17}$ Wells (1998, p. 297).

${ }^{18}$ Finn (1994, p. 102-103).

19 apud La Grange (2005, p. 25).

${ }^{20}$ Barthes (1995, p. 705-718).

${ }^{21}$ Barthes usa o termo "ravissement" num dos Fragmentos de um Discurso Amoroso, onde defende o sujeito apaixonado e o seu discurso. Nesse livro clássico, Barthes mostra a equivalência histórica que há entre o amor e a guerra, já que desde os tempos ancestrais, tanto no amor quanto na guerra, o que existe é a captura e a conquista. E Barthes acrescenta que "ravissement" é algo próximo da fascinação, do encantamento, da loucura. Claro que, em francês, "ravissement" é igualmente "sequestro" e, no caso do discurso amoroso, da disponibilidade do sujeito ao rapto.

${ }^{22}$ Johnson, (2008, p. 236). 